SISTEMA
ELETRONIICO
DE REVISTAS
SER I UfPR

\title{
Plantas alimentícias e paisagens: uso e conservação no Sertão do Ubatumirim, Ubatuba, Brasil
}

\section{Food plants and landscapes: use and conservation in Sertão do Ubatumirim, Ubatuba, Brazil}

\author{
Gabriela Silva Santa Rosa MACEDO ${ }^{1 *}$, Lin Chau MING ${ }^{2}$ \\ ${ }^{1}$ Doutoranda em Ambiente e Sociedade, Núcleo de Estudos e Pesquisas Ambientais (NEPAM), Universidade de Campinas (UNICAMP), \\ Campinas, SP, Brasil. \\ 2 Departamento de Horticultura, Universidade Estadual Julio de Mesquita Filho (UNESP), Botucatu, SP, Brasil. \\ *E-mail de contato: gabrielasantarosa3@gmail.com
}

Artigo recebido em 6 de fevereiro de 2019, versão final aceita em 25 de outubro de 2019.

RESUMO: O manejo de plantas alimentícias por populações tradicionais é crucial para a conservação da biodiversidade, especialmente em áreas consideradas "hotspots", onde a biota única possui alto grau de endemismo. Discutimos aqui como, entre os fatores que contribuíram consideravelmente para a configuração da paisagem socioecológica (entre os anos de 1966 e 2011), a existência de áreas protegidas (Núcleo Picinguaba/Parque Estadual da Serra do Mar e do Parque Nacional da Bocaina) e a dinâmica de manejo para atividade agrícola da comunidade caiçara residente (caracterizada pela diversidade e pelo potencial de conservação de espécies de plantas por meio do uso contínuo) tiveram importância considerável. Partimos do pressuposto de que o uso continuado e in situ das plantas alimentícias seriam fatores-chave para a conservação da biodiversidade (alfa) de espécies arbóreas, apontando outros condutores atuantes no sistema socioecológico analisado nesta pesquisa. Os dados foram obtidos por meio da observação participante, questionários e entrevistas. Utilizamos o geoprocessamento a fim de correlacionar critérios êmicos de distinção da paisagem com aspectos fitossociológicos, de cobertura florestal e de diversidade. Todos esses fatores indicaram que esses agricultores deveriam ocupar posições importantes de participação para tomadas de decisões ligadas à conservação da biodiversidade nessas unidades de conservação.

Palavras-chave: caiçara; áreas protegidas; manejo plantas alimentícias; cobertura florestal.

ABSTRACT: The management of food plants by traditional communities is crucial for biodiversity conservation, especially in locations where the unique biota has a high level of endemism. There are many factors responsible for changes on the local landscape during the years of 1966 to 2011. We discuss how protected areas (Picinguaba 
Nucleus of the Serra do Mar State Park and Bocaina National Park) and the traditional smallholder farmers' (caiçaras) management affected this scenario. We assume that continuous and in situ use of food plants are key factors for maintaining local biodiversity and we point out other drivers acting on this socioecological system, which is analyzed on this research. We collected data through participant observation, questionnaires and interviews. We used geoprocessing tools for linking landscape distinction emic criteria with phytosociological aspects, forest cover and diversity. These factors indicate that caiçara farmers should have a voice in decisions related to biodiversity conservation in both parks.

Keywords: caiçara; protected area; food plant management; forest cover.

\section{Introdução}

Com a Convenção sobre a Diversidade Biológica (CDB), Estados-Nação reconheceram a ligação intrínseca entre a conservação da biodiversidade e a existência de populações humanas nos locais onde, notadamente, há maior conservação (Balmford et al., 2005; Butchart et al., 2010; Fischer et al., 2012). Importantes discussões que permearam os debates sobre conservação, antes e durante a CDB, foram resultado do processo histórico de mobilizações sociais iniciados por grupos sociais que vinham buscando o reconhecimento de direitos fundiários, proteção de territórios e de recursos naturais (Allegretti, 2008; Foppa et al, 2018). Além disso, foram apontados problemas no enfoque da conservação ex situ em detrimento da in situ (Clement et al., 2000). Nesse debate, alguns autores procuram focar no fato de que, independente de diferentes definições de conservação in situ, ex situ e on farm, a continuidade do uso dos determinados recursos genéticos é que seria a garantia da conservação de determinadas espécies de plantas (Clement, 1999; Clement et al, 2000; Galluzzi et al., 2010; Johns et al., 2013; Dawson et al., 2014) e dos recursos naturais presentes (Ostergard et al., 2009; Altieri $\&$ Toledo, 2011).

Associadas a locais como "hotspots" (Myers et al., 2000), estão populações tradicionais que, historicamente, têm estabelecido uma relação íntima de interação com o meio natural, a partir da qual é gerado um tipo de conhecimento como resultado de sua adaptação ao ecossistema. Baseado nesse conhecimento local, elas praticam uma forma de agricultura caracterizada por apresentar elevada diversidade inter e intra específica de plantas cultivadas (Peroni \& Martins, 2000; Bernholt et al., 2009; Brussaard et al., 2010; Ratnadass et al., 2012; Ng'endo et al., 2015; Shen et al., 2017). Dessa forma, essas populações criam formas de manejo de áreas na qual tais práticas de manejo estão profundamente ligadas à continuidade dos processos naturais do meio (Saxena et al., 2016), considerado, assim, um sistema socioecológico'.

Ainda que nos últimos anos tenhamos avanços na constatação da premissa acima (Faith et al., 2010; Schroth \& Mota, 2013; Moreno-Calles et al., 2016) com a implementação de Unidades de Con-

\footnotetext{
${ }^{1}$ Definido como: "sistemas ecológicos intensamente influenciados pelas atividades humanas em que se registra uma não menos forte dependência dos sistemas sociais em relação aos recursos e aos serviços providenciados pelos ecossistemas" (Berkes et al., 2003; Farral, 2012; Buschbacher, 2014).
} 
servação (UC) de Uso Sustentável, ainda há muitas UCs no Brasil e no mundo cuja legislação, visando unicamente a proteção dos recursos naturais, deixa de lado as populações que residem no interior destas. Uma grande dificuldade para esses povos está na obtenção de alimento, seja no cultivo ou na extração de espécies de plantas no interior de florestas. Assim, a integração da agricultura tradicional com os paradigmas da conservação biológica ainda é um problema de extrema relevância (Raymond $e t$ al., 2009; Jackson et al., 2012; Reed et al., 2016; Anaya \& Espirito-Santo, 2018).

Logo, a presença dessas populações em áreas de preservação de remanescentes florestais, como o Parque Estadual da Serra do Mar (PESM), ao mesmo tempo em que se constitui como uma ferramenta para a conservação da biodiversidade, também representa um desafio quando se pretende conciliar visões diferentes sobre o acesso e uso de recursos naturais.

Tendo em vista, ainda, que o manejo pode diferir entre comunidades, seja por diferenças geográficas ou culturais (Casas et al., 1998; Casas et al., 2007), o presente trabalho procurou explorar os seguintes questionamentos: 1) de que forma a população caiçara residente no interior e entorno do PESM obtém espécies de plantas alimentícias importantes para sua base alimentar?; 2) como a paisagem vem sendo modificada estando presente o manejo destas espécies?; 3) como o manejo destas espécies contribui para a conservação da sociobiodiversidade?

\section{Metodologia ${ }^{2}$}

\section{1. Área de estudo}

O local do estudo abrange áreas de duas Unidades de Conservação - Parque Estadual da Serra do Mar/ Núcleo Picinguaba (PESM/NPic) e ainda do Parque Nacional da Serra da Bocaina (PNSB). As UCs apresentam sobreposição em alguns pontos, o que gera conflitos entre as duas em decorrência das diferentes legislações que permitem ou não a permanência de comunidades locais/tradicionais no interior dos parques. Somente o PESM possui hoje em seu Plano de Manejo um zoneamento que possibilita uma área para que as populações residentes desenvolvam seu modo de vida, ainda que haja restrições quanto ao uso de recursos naturais cujas permissões ficam sujeitas à aprovação de órgãos ambientais.

O Parque Estadual da Serra do Mar (PESM) (Figura 1) foi criado pelo Decreto Estadual $\mathrm{N}^{\circ}$ 10.251 de 30 de agosto de 1977 e é administrado pela Fundação Florestal. Após o Decreto 56.572/2010, a unidade passou a abranger 11 núcleos (Bertioga, Caraguatatuba, Cunha, Curucutu, Itariru, Itutinga Pilões, Padre Dória, Picinguaba, Santa Virgínia, Caminhos do Mar e São Sebastião), sendo 10 deles núcleos administrativos. PossuiTem uma área correspondente a 315.390 hectares, abrangendo parte de 23 municípios. É situado na porção leste do Estado de São Paulo, na escarpa da Serra do Mar, o Parque ocupa pequenas porções do planalto atlântico e planície costeira adjacentes, apresentando continuidade com as florestas remanescentes do litoral e do planalto fora de seus limites. Dentro do Parque Estadual da Serra do Mar encontram-se

${ }^{2}$ Para este estudo, foram obtidos: 1) Parecer Substanciado do Comitê de Ética em Pesquisa (n. 265.786 de 22/04/2014); 2) Autorização SISBIO n. 38611-1; 3) Autorização COTEC (PESM/Instituto Florestal, n. 260108-003.443/2013); 4) Autorização IPHAN (n. 05 de 28/02/2014). 
todos os tipos de vegetação existentes na região costeira: floresta ombrófila densa, restinga, campo de altitude, manguezal e várzea.

O PNSB foi criado em data anterior ao PESM, pelo Decreto n. 70.694 de 8 de junho de 1972, com área de 104.000 ha (Brasil, 2014) e foi acompanhado pela construção da Rodovia Rio-Santos (BR101) nos anos de 1970, e esta, por sua vez, serviu de incentivo à especulação imobiliária na região (Silva, 2005). Ambos os projetos tiveram o cunho político conservador que refletiam o objetivo de ampliação do projeto nacional-desenvolvimentista iniciado pelo Governo Militar da década de 1960 (Ferreira et al., 2001).

O bairro do Sertão do Ubatumirim, localizado no município de Ubatuba/São Paulo, abriga em sua maior parte agricultores caiçaras, aos quais foi designada a Zona Histórico Cultural Antropológica (ZHCAn) no Plano de Manejo do PESM para o manejo de plantas e paisagens. Essa zona só foi, de fato, legitimada após a conclusão do Plano de Manejo da UC. Neste, é previsto que as práticas agrícolas poderão ser permitidas quando forem considerados os atributos ecológicos da localidade, mediante autorização dos órgãos competentes, que avaliarão também a existência de práticas de conservação dos solos. A coleta de sementes também passa por regulamentação que determina que a atividade poderá ser autorizada a depender do local, época e quantidades (São Paulo, 2008).

A comunidade de agricultores apresenta documentos (como certidões de nascimento) que comprovam mais de 100 anos de ocupação na região. Cultivam tradicionalmente uma grande quantidade de etnovariedades de banana, das quais um volume expressivo é comercializado no município de Ubatuba, nas feiras livres.
As áreas mais antigas de bananal tradicional estavam ao longo da chamada Trilha do Corisco ou Linha do Telégrafo, estrada de trilha antiga que ligava essa região ao município de Parati, no estado do Rio de Janeiro, para onde as bananas eram levadas com o auxílio de animais ou carregadas nas costas dos agricultores para serem vendidas na cidade. A comunidade é conhecida na região por ter sido uma das poucas que entraram em embate direto com as UCs para garantirem a continuidade das práticas agrícolas.

Dessa forma, dentre as comunidades da região, foi escolhida apenas a comunidade caiçara do Sertão do Ubatumirim para os propósitos deste estudo em virtude dos seguintes critérios: longo tempo de residência na região, manejo expressivo de espécies alimentícias, histórico de conflito e resistência frente às restrições impostas pelas UCs mantendo, assim, os cultivos de roças e bananais.

\subsection{Coleta e análise de dados}

A partir da abordagem etnoecológica foi feita observação participante, interpretação e análise das atividades de manejo tendo como ponto de entrada as unidades familiares. As atividades realizadas envolveram reconhecimento e rapport da pesquisadora com a comunidade, coleta de dados sociais, ecológicos e geográficos.

A amostragem foi definida por meio do procedimento denominado "bola de neve" e por julgamento (Bernard, 2006), na qual se buscou agricultores(as) identificados(as) pela comunidade como especialistas nas atividades de manejo de espécies alimentícias.

A amostragem de agricultores(as) tradicionais envolveu aqueles(as) que estavam realizando o cul- 
tivo e manejo dessas plantas. A suficiência amostral foi atingida com 23 entrevistados (a partir do ponto em que se atingiu a estabilidade do número de citações de espécies) em 3 faixas de idade: até 36 anos (17\% homens), entre 36 e 50 anos (9\% homens e $9 \%$ mulheres) e acima de 50 anos (43\% homens e $22 \%$ mulheres).

Foram realizadas entrevistas estruturadas e semi-estruturadas de caráter quantitativo e qualitativo (Bernard, 2006) com os membros encarregados pelo cultivo/ manejo de plantas alimentícias e com os responsáveis pelas decisões a respeito dos locais de intervenção. Também foram aplicados questionários e feitas entrevistas semi-estruturadas com o gestor do PESM-Núcleo Picinguaba, com dois agentes da administração da organização da comunidade (Associação de Bananicultores de Ubatumirim- ABU) e com a coordenadora de projetos da Organização Não Governamental mais atuante junto à $\mathrm{ABU}$ (nesse caso, o Instituto de Ecovilas e Permacultura da Mata Atlântica- IPEMA), totalizando 4 entrevistados.

Foram realizadas coletas botânicas e identificação das espécies encontradas. Para tanto, houve o acompanhamento de um mateiro e foi feita consulta ao herbário da Escola Superior de Agronomia Luiz de Queiroz (ESALQ), localizado em Piracicaba-São Paulo, para a identificação botânica.

Nos ambientes agrícolas e florestais foram levantadas informações detalhadas sobre técnicas e tecnologias (conhecimentos, procedimentos e materiais) de cultivo, calendário agrícola (plantio, colheita, manejo) e variedades de espécies cultivadas e/ou manejadas.

Em entrevistas estruturadas foi utilizado o método da "listagem livre" (Bisol, 2012) junto aos agricultores caiçaras a fim de obter informações sobre os elementos/espécies culturalmente mais importantes no universo de cada unidade amostral. Utilizando o software Anthropac 1.0 foram calculados frequência, ranking e saliência.

Os Índices de Saliência obtidos foram divididos em classes de intervalo em ordem crescente de importância. Essas classes estão relacionadas a rupturas de itens do domínio cultural estabelecidos pelo informante, de acordo com a importância cultural (Morais et al., 2009). Utilizando a Interface Gráfica Tinn R (Faria et al., 2014) e o programa estatístico R (R Core Team, 2014), foi obtida a matriz de contingência a partir do cruzamento da forma de obtenção das espécies citadas e dos Índices de Saliência das mesmas. A partir desta, foi feita a análise de correspondência (Nenadic \& Greenacre, 2007) e obtido o gráfico correspondente.

Foram demarcadas parcelas circulares com $10 \mathrm{~m}$ de raio nas áreas de paisagens de reconhecimento êmico. A opção por esse tipo de parcela se baseou na menor razão perímetro/área para menor erro por efeito de borda. Foram identificadas 4 paisagens onde os agricultores manejavam e/ou cultivavam espécies alimentares: capoeira, bananal, quintal e roça. Levando em consideração o histórico de ocupação e intervenção por meio de cultivo e manejo do Sertão do Ubatumirim, essas paisagens foram encontradas em duas faixas altitudinais: Terra Baixa (TB) e Submontana (SM). Em cada uma dessas faixas foram sorteadas e demarcadas 3 parcelas/área para as diferentes fisionomias vegetais nas 8 áreas (4 para cada domínio vegetal) mais uma parcela controle (capoeira com mais de 20 anos sem manejo), totalizando 27 parcelas. Os indivíduos utilizados para esse estudo foram os que apresentaram Diâmetro à Altura do Peito $(\mathrm{DAP}) \geq 5 \mathrm{~cm}$. 


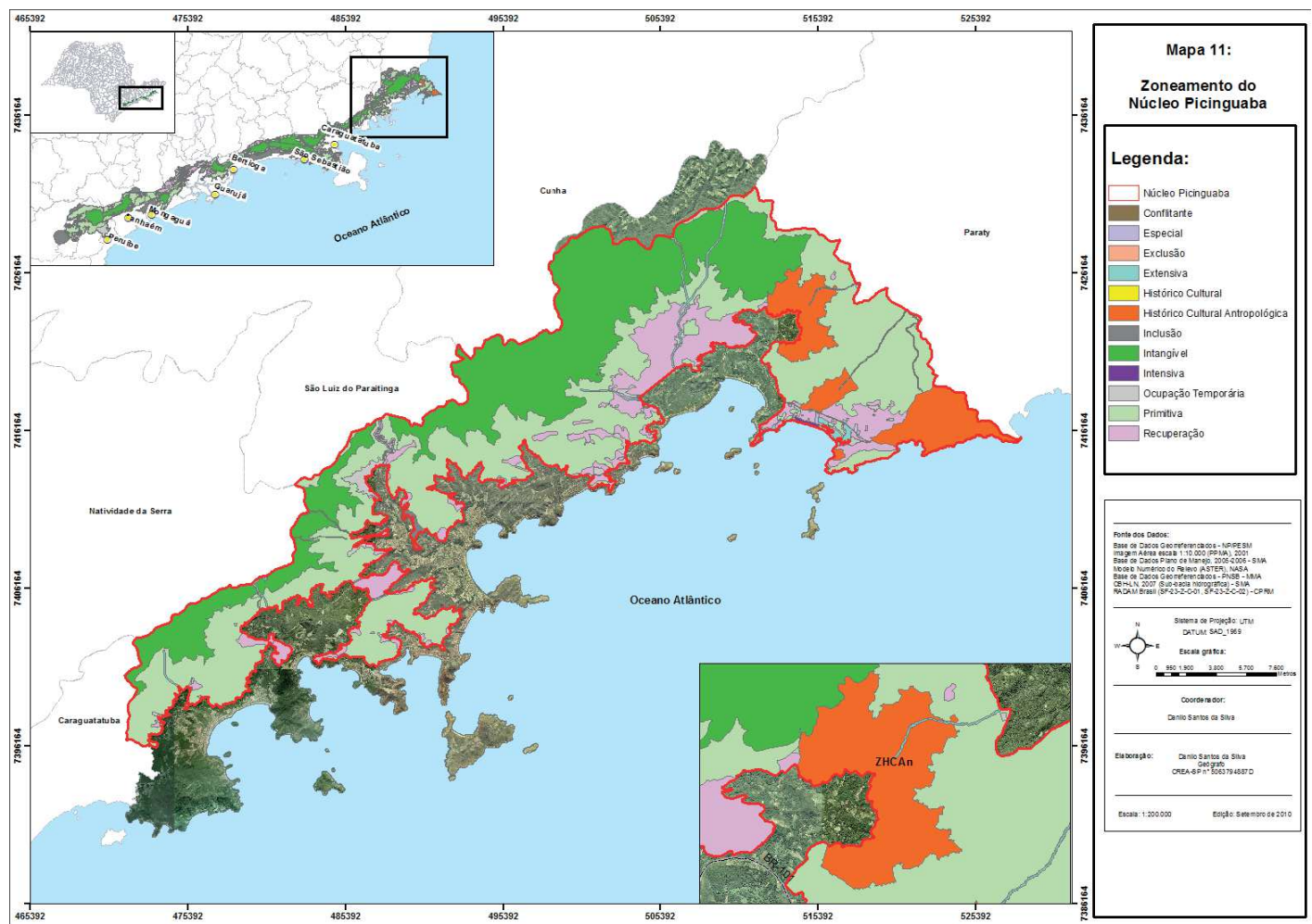

FIGURA 1 - Mapa do Zoneamento do Parque Estadual da Serra do Mar, Núcleo Picinguaba- São Paulo. Destaque da Zona Histórico Cultural Antropológica (ZHCan). Sistema de Projeção UTM DATUM SAD 1969. Escala: 1:200.000. Elaboração: Danilo Santos da Silva, 2010. FONTE: Silva (2010, p. 73).

Para fins de análise de diversidade, considerando os componentes riqueza e abundância, foi realizado levantamento fitossociológico e foram utilizados os índices de diversidade de Shannon-Wiener, Simpson e de Equidade gerados a partir do software PAST (Hammer et al., 2001).

O método "walk-in-the-woods" (Phillips \& Gentry, 1993; Albuquerque \& Lucena, 2004) foi utilizado para validação dos nomes das plantas e paisagens citadas nas entrevistas, já que o nome vernacular de uma espécie pode variar bastante entre regiões e até mesmo entre indivíduos de uma mesma comunidade. Tal método também auxiliou na descrição do sistema de identificação e interpretação da paisagem feita pela população local e seu relacionamento com os aspectos culturais da comunidade. Associados a esses locais, foram colhidos dados pelo sistema de posicionamento geográfico (GPS) para localização das áreas de manejo. O geoprocessamento foi utilizado para elaboração dos mapas de cobertura florestal na região do Sertão do Ubatumirim em diferentes períodos.

Para a elaboração dos mapas onde estão situadas as áreas de manejo utilizadas para o levanta- 
mento fitossociológico, foram utilizadas fotografias aéreas cedidas pelo Parque Estadual da Serra do Mar - Núcleo Picinguaba (PESM-NPic), de 1966 e 1977, além de uma imagem proveniente do Google Earth, de 2011. O software utilizado foi o ArcGis 9.3. O datum de referência horizontal utilizado foi SIRGAS 2000, zona 23k, Projeção UTM.

\section{Resultados e discussão}

\subsection{Obtenção das espécies hortícolas alimentares}

Para os agricultores caiçaras do Sertão do Ubatumirim, a continuidade dos processos ecológicos dentro das áreas de manejo é fator fundamental, que contribui diretamente nas formas de obtenção de renda e alimentos dos núcleos familiares. Assim, as práticas cotidianas da população estudada podem apontar caminhos mais seguros para a elaboração de propostas e estratégias visando a exploração sustentável dos recursos vegetais. Por isso, conhecer as formas de obtenção de plantas alimentícias e as partes utilizadas dessas espécies é necessário para se compreender sobre o uso de plantas e suas consequências sob fatores como a diversidade.

As 259 etnovariedades citadas foram distribuídas quanto à forma de obtenção nas categorias Cultivada (C) (70,3\%), Extraída (E) (10,15\%) e Extraída/Cultivada (19,53\%). Essas atividades são comuns em comunidades locais, uma vez que se trata da manipulação humana nas unidades de paisagem a fim de garantir alimento, e podem ser consideradas como vias de promoção de segurança alimentar, fator essencial para sua sobrevivência (Thrupp, 2000; Little, 2002; Altieri, 2004).
É importante destacar que, eventualmente, os agricultores consomem espécies de plantas obtidas em mercados (quando não são cultivadas pela família agricultora) ou na feira de Ubatuba, além do consumo de carnes compradas de pescadores ou em açougues. O consumo de alimentos oriundos das áreas urbanas nas proximidades de comunidades rurais vem sendo apontado por alguns autores como crescente em algumas localidades (Sampaio et al., 2006; Pilla \& Amorozo, 2009). Esse fato teria, então, implicação direta nas questões de segurança ou mesmo de insegurança alimentar.

A análise da listagem livre mostrou que o domínio cultural da comunidade se concentra nestas 259 etnovariedades. A partir do Índice de Saliência (IS), foi possível visualizar rupturas das espécies alimentícias formando agrupamentos em 4 classes (qui-quadrado $=13.0545 ; \mathrm{df}=6 ; \mathrm{p}=0.04218$ ). Sendo: $\mathrm{S} 1$ com IS entre 0 e 0,0831 , o grupo das que foram menos citadas; S4 com intervalo entre 0,247 e 0,822, o grupo das mais citadas; S2 entre 0,0831 e 0,165 e S3 entre 0,165 e 0,247, como grupos intermediários.

$\mathrm{Na}$ análise de correspondência entre os grupos de ruptura vê-se que os grupos S4 (maiores saliências), S2 e S3 (valores intermediários de saliência) estão mais próximos das categorias de obtenção C e E. O grupo S1 (menores saliências) está mais próximo do grupo de obtenção $\mathrm{E}$ do que os demais agrupamentos (Figura 2). Esse fato reforça a premissa de que as plantas que ganham importância dentro de uma cultura tendem a ser cultivadas, o que também pode levar a uma maior dependência dessas espécies e/ou variedades em continuar existindo por meio da manipulação humana sobre elas, como é o caso das etnovariedades de mandioca encontradas em outras comunidades locais/tradicionais (Peroni \& Hanazaki, 2002). 
Muitas das etnovariedades mais citadas são altamente dependentes do cultivo devido ao grau de domesticação em que se encontram, como as mandiocas (Manihot esculenta Crantz), bananas (Musa spp.), carás (Dioscorea spp.), e inhames (Colocasia sp.). Outras, como a juçara (Euterpe edulis Mart.) e o cambuci (Campomanesia phaea (O. Berg) L.R. Landrum), com Índices de Saliência de 0,22 e 0,43 , respectivamente, foram muito citadas devido à grande participação na economia das famílias.

As espécies que são coletadas na floresta (como a juçara, cujo consumo é prioritariamente de frutos), ganham importância na cultura da comunidade, passam a ser cultivadas, chegando a um nível de importância dentro das áreas de manejo próximas àquelas que historicamente vem sendo cultivadas pela comunidade. No entanto, essa importância é recente, ganhando força nos últimos anos em decorrência dos incentivos dados por projetos de organizações não governamentais e por programas e políticas públicas voltadas ao fortalecimento da segurança alimentar das comunidades e à conservação da Mata Atlântica.

A partir das citações, o Índice de Saliência apontou que as espécies mais importantes para a comunidade são as bananas, mandiocas, carás, juçara, inhame, cambuci e jabuticaba (Plinia trunciflora (O. Berg) Kausel), com Frequência unânime $(100 \%)$ para as bananas ouro e prata. Fato similar foi observado por Peroni e Hanazaki (2002) em estudo com caiçaras da Mata Atlântica. Os autores destacam um consumo crescente de espécies não cultivadas e sugerem que a causa possa estar na

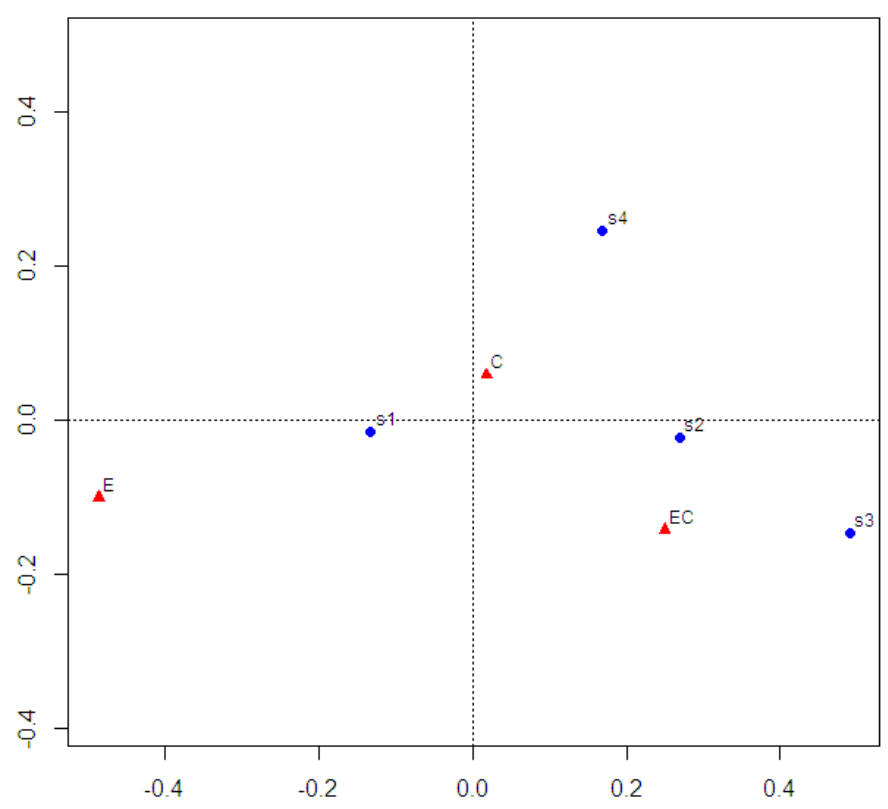

FIGURA 2 - Análise de correspondência entre Índice de Saliência e Formas de Obtenção de espécies alimentares citadas pelos entrevistados do Sertão do Ubatumirim, Ubatuba/SP, 2014. 
redução de cultivo devido às restrições ambientais que limitam as práticas agrícolas de populações locais que vivem em áreas que se tornaram UC.

O grupo $\mathrm{S} 1$ (menor IS), mais próximo do grupo das Cultivadas e do grupo das Extraídas do que todos os outros grupos, são plantas menos comuns no dia a dia e menos comercializadas pela comunidade do Ubatumirim. No entanto, são mantidas pelos caiçaras, com importância cultural para a comunidade. Tal fato sugere a necessidade de uma investigação aprofundada sobre os hábitos alimentares da população para que seja verificada a diversidade que é mantida na alimentação das famílias.

As partes das plantas que são consumidas variam desde o consumo de fração da planta até a totalidade desta. Houve predominância nas citações de espécies cujo consumo é majoritariamente de frutos (59,84\%), seguido pelo consumo de sementes (10,98\%). Outros autores também encontraram um consumo maior de frutos em detrimento das outras partes (Ferreira \& Jardim, 2005; Amaral \& Neto, 2008). Estudos como esses, em que se amplia o conhecimento sobre espécies e formas de preparo destas, têm importância por poder gerar mais ferramentas para futuros programas de segurança alimentar, tendo em vista que consideram as preferências alimentares (Taylor et al., 2005; Beveridge et al., 2013), de mercado (Evans, 1996; Ruiz-Pérez et al., 2004) e até mesmo o potencial de consumo de outras plantas e/ou partes destas pouco reconhecidas como alimentícias (Kinupp \& Barros, 2004).

\subsection{Cobertura florestal das áreas de manejo}

Foram selecionadas 3 imagens com a área do Sertão do Ubatumirim de diferentes datas que marcam os períodos de uso e ocupação do território. Uma anterior a implantação das Unidades de Conservação (1966) (Figura 3), uma do período de implantação das UCs (1977) (Figura 4) e outra mais recente da mesma área (2011) (Figura 5).

Entre os anos de 1966 e 1977, observa-se um avanço da derrubada da área florestal nas zonas de baixada (faixa inferior a 100m de altitude), externas aos limites das UCs, e um aumento do desmatamento em áreas no interior das UCs (à direita no mapa). A redução da cobertura florestal, nesse período, pode ter sido causada por diversos fatores, podendo estes serem internos, como o aumento da população rural residente, quanto por externos à comunidade caiçara, por exemplo, pela construção da Rodovia Rio-Santos (BR-101), nos anos de 1970.

Segundo Siqueira (1984), a construção da Rodovia Rio-Santos fez a especulação imobiliária na região litorânea crescer em ritmo acelerado devido à grande procura por terrenos nas proximidades das praias de Ubatuba e já era prevista como consequência do impulsionamento do turismo mesmo antes da consolidação da rodovia. Assim, grandes empresas passaram a comprar porções de terra nesses locais visando a valorização futura que o turismo traria.

Além disso, a população migrante em Ubatuba vem crescendo ao longo dos anos e há uma estimativa de aumento populacional, com aumento da densidade demográfica (Tabela 1) nos próximos anos, chegando a mais de 110.000 habitantes até 2025, um dos maiores crescimentos em comparação aos municípios adjacentes como Caraguatatuba, Ilha Bela e São Sebastião (São Paulo, 2010).

A população rural em Ubatuba passou também por variações consideráveis. No ano de 1960, havia 3.801 pessoas residindo na zona rural e esse número aumentou para 6.120 pessoas no ano de 1970 (Bra- 
sil, 2019). Por se tratar de áreas de bairros rurais, não há controle do número de novos moradores, o que justifica o aumento populacional no Sertão do Ubatumirim, apontado pelos entrevistados desta pesquisa. Segundo os mesmos, por serem locais de acesso fácil, a população que chegou ao bairro, nesse período, facilmente se estabeleceu, principalmente nas faixas altitudinais de baixada, já que as cotas mais altas já haviam sido ocupadas pelos agricultores caiçaras do sertão.

A partir da década de 1980, vê-se que a população rural já era aproximadamente duas vezes e meia menor do que na década anterior, período em que as duas Unidades de Conservação já haviam sido criadas (Tabela 1). No período de criação das UCs, o Estado ainda fazia pouco investimento para a fiscalização e monitoramento de desmatamento, o que pode ter contribuído para a redução da cobertura florestal na imagem de 1977 (cinco anos após criação do PNSB) em relação a de 1966.

Em 1977, com a criação do PESM, a área de proteção no Sertão do Ubatumirim se amplia abrangendo cotas altitudinais mais baixas e, pouco depois, entre os anos de 1980 e 1991, há uma queda drástica na taxa de crescimento anual dessa população que voltou a crescer entre os anos de 1991 e 2000 (Tabela 1), mas ficando ainda em patamares inferiores aos da década de 1960. Há variações na taxa de crescimento rural em valores negativos e positivos, porém o mesmo não ocorre com a densidade demográfica de Ubatuba, onde o aumento de população esteve sempre crescente nos períodos destacados aqui.

Nas imagens que marcam a cobertura florestal no ano de 2011, percebe-se uma recuperação da cobertura florestal nas áreas de baixada e nas áreas dentro dos limites das UCs onde havia desmatamento na imagem de 1977, o que poderia sugerir um importante papel de dois fatores (ainda que possivelmente não sejam os únicos): a) o da contenção do desmatamento causado pela exploração e especulação imobiliária sob essas áreas após a consolidação das duas UCs; b) pela redução da pressão de intervenção que havia sido ampliada com o aumento populacional nas áreas rurais entre as décadas de 1960 e 1970.

TABELA 1 - Variação das Taxas de Crescimento Anual da População Rural de Ubatuba-SP. Fonte: Informações dos Municípios Paulistas da Fundação SEADE (São Paulo, 2019) e IPEA (Brasil, 2019).

\begin{tabular}{ccccc}
\hline \multirow{2}{*}{ Ano } & $\begin{array}{c}\text { Densidade Demográfica } \\
\text { (habitantes/km2) }\end{array}$ & $\begin{array}{c}\text { Grau de Urbanização } \\
\text { (\%) }\end{array}$ & $\begin{array}{c}\text { Taxa Geométrica de Crescimento Anual da } \\
\text { População Rural (em \% a.a.) }\end{array}$ \\
\cline { 4 - 5 } & 37,81 & 90,9 & $\mathbf{1 9 8 0 - 1 9 9 1}$ & $\mathbf{1 9 9 1 - 2 0 0 0}$ \\
\hline 1980 & 65,92 & 97,64 & $-6,94$ & \\
1991 & 93,59 & 97,51 & & 4,58 \\
2000 & 108,72 & 97,6 & & 1,31 \\
\hline
\end{tabular}

FONTE: Elaborado pelos autores. 
Nas 3 imagens da cobertura florestal, as parcelas demarcadas para este estudo, que representam as áreas de manejo em uso nos dias atuais (polígonos em vermelho na imagem de 2011), apresentaram pouca variação da cobertura florestal nos 3 períodos. É importante ressaltar que os agricultores caiçaras entrevistados e responsáveis pelo manejo dessas áreas residem no local há pelo menos duas gerações, com baixa migração desse grupo para áreas urbanas. Isso representa uma continuidade das práticas locais de cultivo de espécies alimentícias dentro do Sertão do Ubatumirim, que envolvia a abertura de áreas e posterior abandono para recuperação da capoeira.

A legislação ambiental trouxe impedimentos para a atividade agrícola itinerante que depende de áreas de floresta secundária (as capoeiras). As roças passaram a ser consideradas ilegais e as multas recorrentes influenciaram na redução da atividade. Os agricultores relatam que não pararam os cultivos das roças e bananais, mas diminuíram a frequência. Enquanto enfrentavam as administrações das UCs na tentativa de terem assegurados os direitos de manterem as práticas locais de agricultura (Simões et al., 2011), os agricultores foram, crescentemente, procurando atividades complementares de renda como o turismo, o trabalho como caseiros, pedreiros, cozinheiras e, alguns, na pesca artesanal. Em toda extensão do litoral brasileiro ocupado por populações tradicionais, o declínio da agricultura itinerante (Peroni, 2004; Suzuki et al., 2010), que afeta o modo de vida de muitas populações tradicionais, tem levado os caiçaras a sustentarem suas famílias com o trabalho assalariado ou a partir da aposentadoria dos mais velhos (Hanazaki et al., 2007).

Carvalho (2014) enfatiza que a criação da UC foi positiva, agindo como contraponto ao impacto causado pela construção da Rodovia Rio-Santos e à especulação imobiliária, descrevendo o modo subjetivo de como os atores sociais envolvidos reagiram à implantação do PESM. Segundo a autora, o setor imobiliário considerou as UCs um empecilho por preservar uma área que poderia ser utilizada para fins de exploração capitalista do território, como por exemplo para a construção de condomínios, e, para as populações locais, a criação do patrimônio público (UCs) durante o período militar marca uma época específica e autoritária de gestão da coisa pública pela restrição de práticas agrícolas e extrativistas tradicionais.

Temos, dessa forma, dois importantes elementos que agem na proteção da biodiversidade, porém atuando de forma contrastante: as leis de UC de Proteção Integral e a forma da população tradicional caiçara manejar espécies e paisagens. Os agricultores caiçaras atuam com técnicas que visam a manutenção da regeneração da paisagem após sua intervenção, por exemplo, com o pousio das áreas de manejo. Os Parques operam demarcando áreas limites de intervenção e exploração de recursos naturais, contendo o aumento do setor imobiliário, no entanto, com normas que tornam excluídas também as práticas dos agricultores caiçaras. Vê-se, aqui, que existe muito mais uma deficiência na interpretação do papel dessas populações, o que pode ser sanado com um reenquadramento do tipo de UC (que poderia, por exemplo, passar a ser de Uso Sustentável, conforme Sistema Nacional de Unidades de Conservação-SNUC) e não do que propriamente da existência de uma UC numa área que já era ocupada por comunidades tradicionais.

No caso do PESM, essa questão tenta ser resolvida com a identificação das áreas de manejo dos agricultores dentro da ZHCAn até que as discussões sobre uma recategorização das áreas onde vivem 
os agricultores caiçaras avancem, permitindo, assim, a implementação de uma UC que concilie conservação com o uso de recursos naturais pelos agricultores. As áreas de produção dos agricultores estão espalhadas por todo o território do Sertão do Ubatumirim e tem papel fundamental para obtenção de alimentos, sendo utilizadas pelas unidades familiares desde antes de 1966, conforme relato dos agricultores, que comprovam a ocupação no local pela comunidade caiçara por mais de 100 anos.

\subsection{A diversidade nas áreas de manejo}

Nas parcelas demarcadas nas unidades de paisagem de reconhecimento êmico, nas quais ocorre manejo frequente das espécies de plantas, foram obtidos os índices de diversidade da cobertura florestal (Shannon, Simpson e Equidade). Foi considerada ainda nesta análise uma área de capoeira como controle na qual nenhuma unidade familiar realiza manejo há mais de 20 anos (Tabela 2).

O Índice de Shannon-Wiener aponta para maior diversidade nas áreas de Terra Baixa (TB), enquanto o de Simpson atribui à capoeira-Submontana (SM) maior diversidade do que a de TB. Sendo as áreas de TB externas aos limites dos parques, a população pode realizar manejo livre das restrições da legislação das UCs. Isso permite que a intensidade e frequência de cultivo e extração seja mais intenso, o que pode levar as áreas a serem enriquecidas com espécies úteis para os agricultores, aumentando a diversidade.

Na roça e bananal de Terra Baixa há equidade expressiva entre as espécies, sendo superior até à área Controle. Os valores das áreas de quintal SB e TB apresentam os menores valores, o que indica haver predominância de uma espécie com relação às outras $(0,658 ; 0,598$, respectivamente). As áreas de roça e de bananal em Terra Baixa alcançaram valores que apontam para uma baixa dominância de espécies. Isso é explicado pelo fato de que os agricultores cultivam, nestas áreas, outras espécies, além de mandioca (roça) e banana (bananal). É comum encontrar consórcio de plantas nessas áreas e agroflorestas nessas unidades de paisagem. Na roça de TB, por exemplo, uma das parcelas sorteadas caiu numa área de cultivo de frutíferas, o que explica a alta diversidade. As áreas de quintal amostradas são intensamente utilizadas pelos agricultores para produção de polpa de juçara (TB) e para banana (SM). Os quintais são áreas intensamente utilizadas pelos agricultores e agricultoras (principalmente as mulheres) para experimentação. Essas áreas apresentam grande número de espécies de plantas, no entanto, neste trabalho, o levantamento considerou somente espécies com DAP $\geq 5 \mathrm{~cm}$, o que deixa de fora uma gama de espécies com os mais diferentes usos.

TABELA 2 - Índices de Diversidade de Simpson, Shannon-Wiener e Equidade para cada área de manejo de reconhecimento êmico dos agricultores caiçaras do Sertão do Ubatumirim, Ubatuba-SP, em faixas altitudinais Terra Baixa (TB) e Submontana (SM).

\begin{tabular}{|c|c|c|c|c|c|c|c|c|c|}
\hline ÍNDICE & $\begin{array}{c}\text { Capoeira- } \\
\text {-SM }\end{array}$ & $\begin{array}{l}\text { Roça- } \\
\text {-SM }\end{array}$ & $\begin{array}{c}\text { Quintal- } \\
\text {-SM }\end{array}$ & $\begin{array}{c}\text { Bananal- } \\
\text {-SM }\end{array}$ & Capoeira-TB & $\begin{array}{l}\text { Roça- } \\
\text {-TB }\end{array}$ & $\begin{array}{c}\text { Quintal- } \\
\text {-TB }\end{array}$ & $\begin{array}{c}\text { Bananal- } \\
\text {-TB }\end{array}$ & Controle \\
\hline Simpson_1-D & 0,880 & 0,596 & 0,704 & 0,775 & 0,878 & 0,926 & 0,758 & 0,923 & 0,957 \\
\hline Equitability $\mathrm{J}$ & 0,895 & 0,767 & 0,658 & 0,661 & 0,847 & 0,947 & 0,598 & 0,947 & 0,8666 \\
\hline
\end{tabular}


A comparação entre duas faixas de altitude (Terra Baixa e Submontana) mostrou uma maior diversidade nas áreas de Terra Baixa, apontado tanto pelo índice de Shannon-Wiener como pelo de Simpson (Tabela 3), indicando que estas apresentam maior riqueza e equidade de espécies. As áreas da faixa Submontana, por outro lado, apresentaram diversidade inferior e distribuição de número de espécies com predominância de uma espécie (Equidade 0, 572).

TABELA 3 - Índices de diversidade médio de áreas de manejo em faixa Submontana (SM), Terra Baixa (TB) e Controle.

\begin{tabular}{lccc}
\hline \multicolumn{1}{c}{ Índices } & SM & \multicolumn{1}{c}{ TB } & Controle \\
\hline Simpson_1-D & 0,688 & 0,845 & 0,957 \\
Shannon_H & 1,983 & 2,892 & 3,654 \\
Equitability_J & 0,572 & 0,715 & 0,866 \\
\hline
\end{tabular}

As áreas de TB apresentam diversidade mais alta do que as áreas de SM, assemelhando-se, assim, à área Controle, na qual as atividades de manejo foram abandonadas há pelo menos 20 anos (Figura 6). Levando em consideração que em ambas as faixas acontecem o manejo das unidades de paisagem e que as áreas de Submontana são protegidas pelas UCs (no qual o desmatamento da floresta provocado pelos agricultores é supostamente reduzido), os resultados dos índices de diversidade apontam para uma tendência de maior intensidade de manejo nas áreas mais baixas do Sertão do Ubatumirim, ou seja, no entorno do PESM. O que pode sugerir também que esse manejo esteja ligado ao cultivo e conservação de espécies arbóreas nas áreas de TB, ou à maior facilidade de acesso e/ou manejo em virtude de ser uma área menos declivosa.

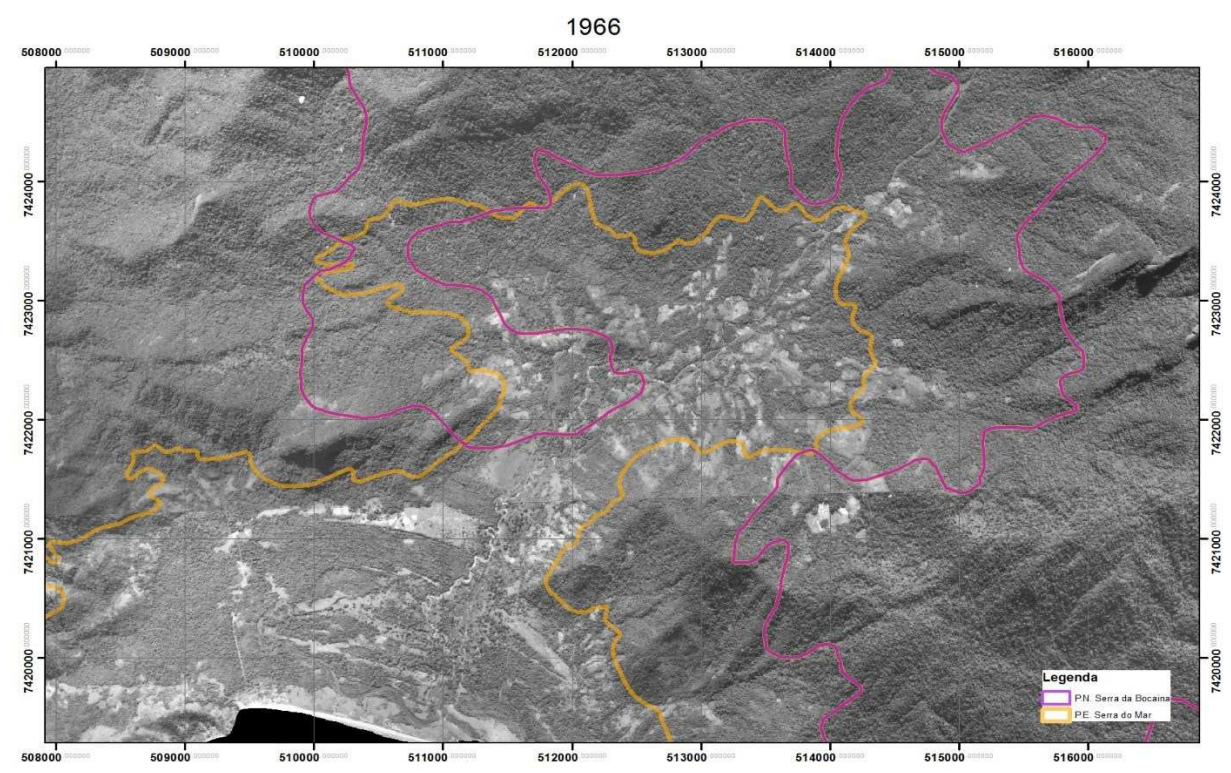

FIGURA 3 - Mapa do Sertão do Ubatumirim com delimitação das áreas de manejo e dos limites do Parque Estadual da Serra do Mar (PESM) e Parque Nacional da Serra da Bocaina (PNSB) no ano de 1966. Escala 1:33.000 (m).

FONTE: Elaboração de Pedro Ivo Rodrigues de Moraes, CREA: 5062954677, 2014. 


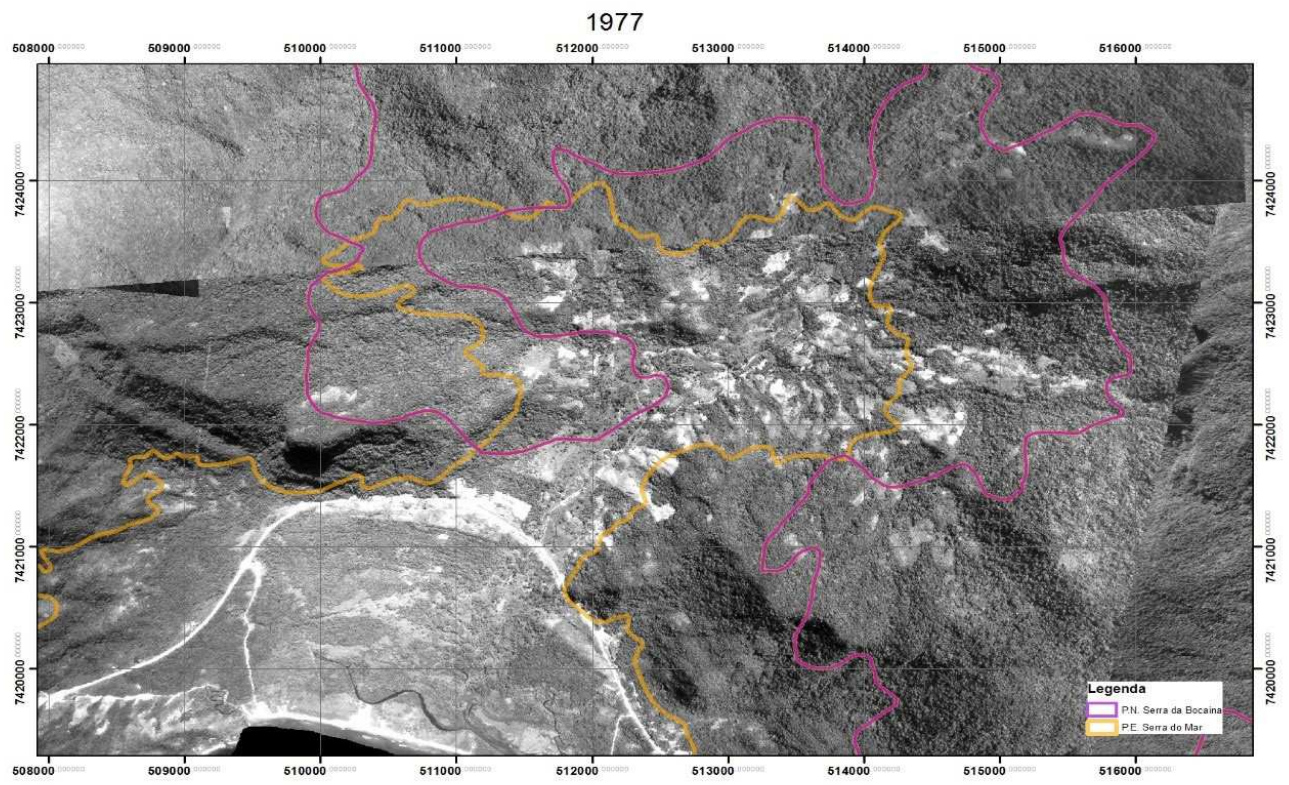

FIGURA 4 - Mapa do Sertão do Ubatumirim com delimitação das áreas de manejo e dos limites do Parque Estadual da Serra do Mar (PESM) e Parque Nacional da Serra da Bocaina (PNSB) no ano de 1977. Escala 1:33.000(m). Pedro Ivo Rodrigues de Moraes, CREA: 5062954677, 2014.

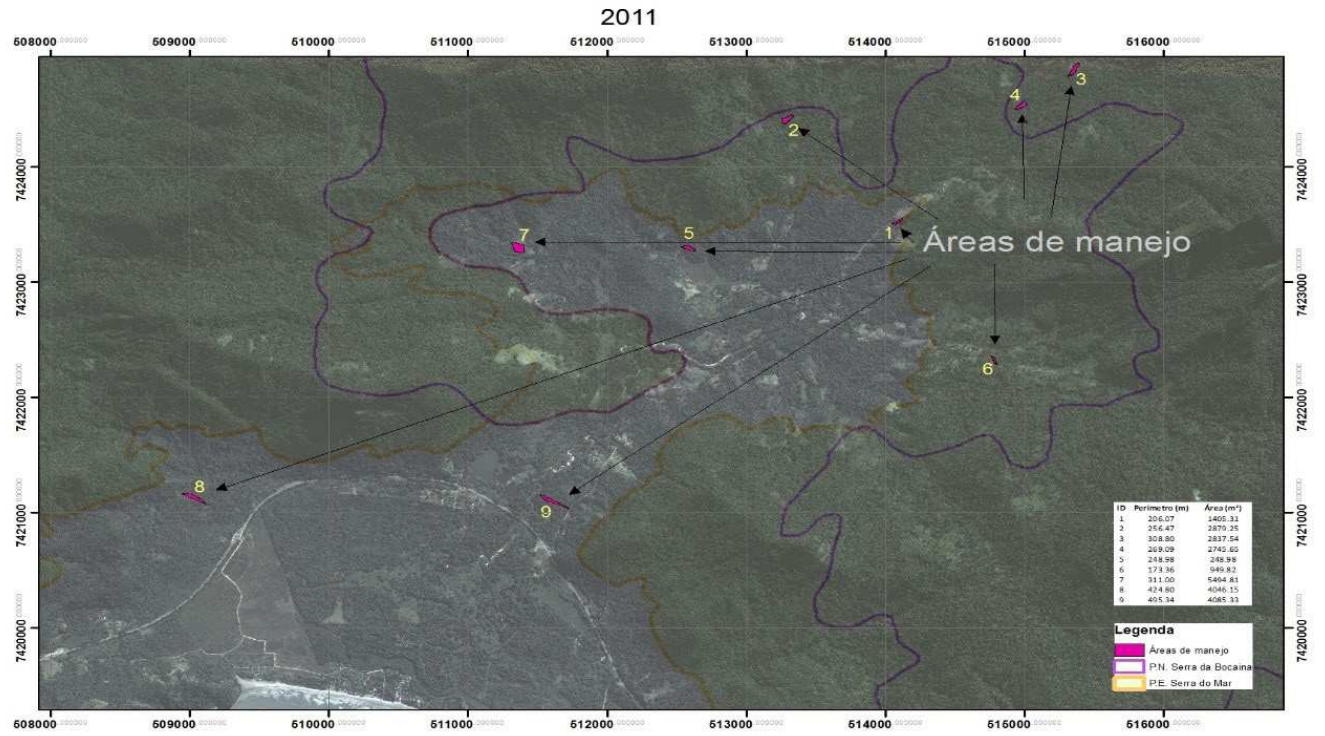

FIGURA 5 - Mapa do Sertão do Ubatumirim com delimitação das áreas de manejo e dos limites do Parque Estadual da Serra do Mar (PESM) e Parque Nacional da Serra da Bocaina (PNSB) no ano de 2011. Pedro Ivo Rodrigues de Moraes, CREA: 5062954677, 2014. Legenda: ID= Identificação da área das parcelas demarcadas para o estudo. Escala= 1:33.000(m). 


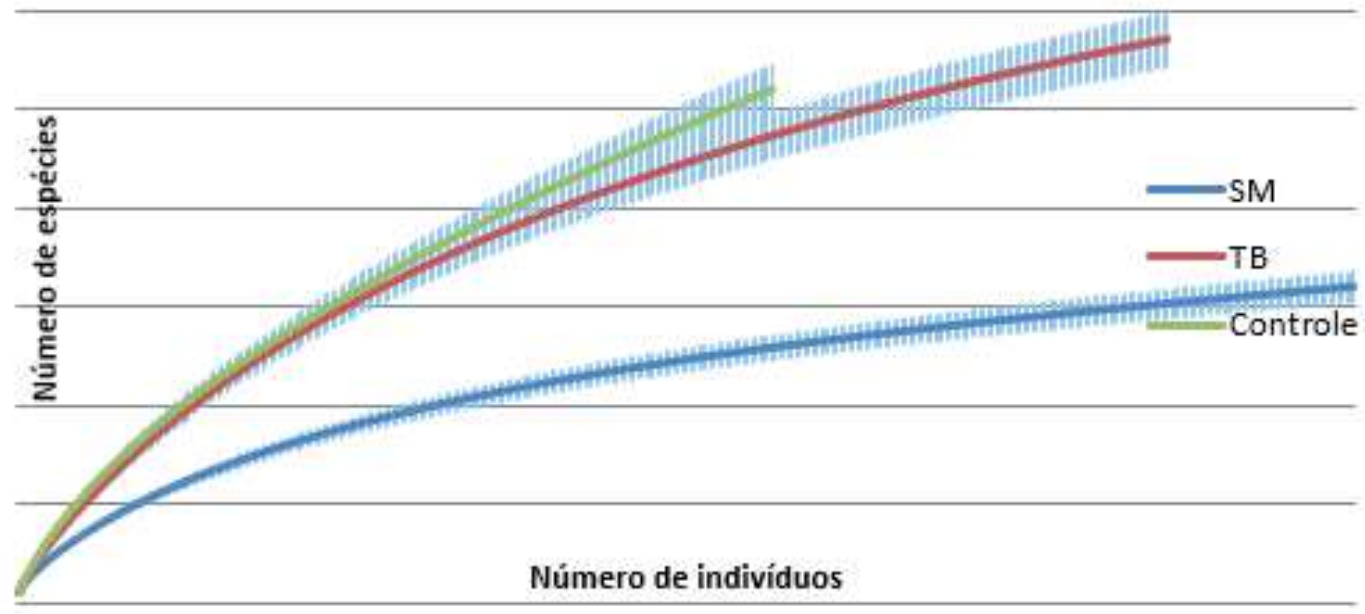

FIGURA 6 - Curva de rarefação individual de diversidade de áreas de manejo em faixa Submontana (SM), Terra Baixa (TB) e Controle. Desvio padrão de $5 \%$.

Pessoa et al. (2008), em estudo comparativo entre uma área manejada e uma área de reserva legal de um assentamento no estado do Rio Grande do Norte (bioma caatinga), encontraram índice de Shannon-Wiener de 1,10 e 0,86, respectivamente. Santos \& Jardim (2006) relataram ter encontrado em floresta de várzea no estado do Pará valores de diversidade de 2,69 (Shannon-Wiener) e 0,63 (Equidade) em área que sofreu intensa intervenção antrópica pela extração de palmito, e chamam a atenção para a importância de se observar diferenças entre áreas manejadas e não manejadas.

O valor do índice de Shannon apontado para TB e SM no Sertão do Ubatumirim é inferior aos encontrados em outros trabalhos na mesma região em Mata Atlântica, onde há pouco ou nenhum tipo de manejo nas áreas (Tabela 4). O valor da área controle deste estudo $(3,65)$ seria o mais próximo do que foi encontrado, por exemplo, por Silva (1980) em áreas de pouco manejo na mesma região. Isto poderia indicar que houve uma recuperação satisfatória do meio em termos de diversidade de espécies de plantas.

Além do fator manejo e tamanho das áreas, valores de diversidade de espécies podem variar em decorrência do alto nível de heterogeneidade ambiental da Serra do Mar, onde variações topográficas, de clima e fertilidade contribuem para o estabelecimento de espécies capazes de ocupar diferentes hábitats (Sanchez et al., 1999). Almeida et al. (2002), no estuário amazônico, relataram que agentes como variação ambiental, inundações e velocidade da água influenciam diretamente em fatores como similaridade entre áreas. 
TABELA 4 - Comparação entre os resultados da análise de diversidade das áreas de manejo do Sertão do Ubatumirim, e levantamentos florísticos de outros trabalhos realizados na Mata Atlântica. Legenda: S= Sim; N= Não; H’= Índice de Shannon-Wiener; J= Equidade.

\begin{tabular}{|c|c|c|c|c|c|}
\hline Local & Área total & $\mathbf{H}^{\prime}$ & $\mathbf{J}$ & $\begin{array}{c}\text { Manejada } \\
(\mathrm{S} / \mathbf{N})\end{array}$ & Referência \\
\hline $\begin{array}{l}\text { Picinguaba (SP) } \\
\text { (Submontana) }\end{array}$ & 2,34 ha & 4,50 & - & $\mathrm{N}$ & Lacerda, 2001 \\
\hline $\begin{array}{l}\text { Ubatuba (SP) } \\
\text { TB } \\
\text { SM }\end{array}$ & 80 quadrantes & $\begin{array}{l}3,49 \\
4,03\end{array}$ & - & $\begin{array}{c}\text { Pouco } \\
\mathrm{N}\end{array}$ & Silva, 1980 \\
\hline Picinguaba (SP) & 0,4 ha & 4,07 & - & $\mathrm{N}$ & Sanchez et al., 1999 \\
\hline $\begin{array}{l}\text { Picinguaba (SP) } \\
\text { (Transição TB/SM) }\end{array}$ & $1 \mathrm{ha}$ & 4,05 & 0,81 & $\mathrm{~N}$ & Campos et al., 2011 \\
\hline $\begin{array}{l}\text { Rio Bonito (RJ) } \\
\text { Prop. Privada } \\
\text { U.C. }\end{array}$ & 0,4 ha & $\begin{array}{l}3,91 \\
4,40\end{array}$ & $\begin{array}{l}0,84 \\
0,87\end{array}$ & $\begin{array}{c}\text { Pouco } \\
\mathrm{N}\end{array}$ & Carvalho et al., 2007 \\
\hline
\end{tabular}

\subsection{Implicações para a conservação}

Dentre os fatores que provocam a redução do cultivo de algumas espécies nas áreas de manejo podemos destacar: a preferência dos consumidores da feira municipal de Ubatuba por algumas espécies e/ou variedades (Macedo \& Ming, 2016); o decréscimo do número de jovens que se dedicam à lavoura; e, os impedimentos das legislações dos Parques para o cultivo de roças, como já mencionado anteriormente.

De acordo com os Planos de Manejo dos Parques, as restrições legais se estendem para todas as atividades de uso de recursos: agrícolas, extrativistas e de caça, sendo que para o PNSB apresenta caráter mais impeditivo e, para o PESM, é limitado por condicionantes que estarão vigentes até que uma recategorização das áreas onde vivem as populações locais seja efetivada Ainda assim, essas restrições (somadas a fatores como a preferência do mercado local, evasão dos jovens do campo, inserção dos agricultores em outras atividades ligadas ao turismo, entre outros) acabam levando os agricultores a procurarem por outras formas de fonte de renda. As atividades agrícola e extrativista dessas populações, que apresentam como característica o manejo de um número considerável de espécies e variedades de plantas, é afetada já que modifica a dinâmica das atividades tradicionais. A redução de tamanho e o tempo de uso das áreas de cultivo, a idade de capoeira permitida de ser utilizada (que está ligada ao tempo de recuperação das áreas que passaram por intervenção) e o tempo para aprovação das solicitações para início dos cultivos das roças são exemplos de causas que podem criar espaço para que os agricultores deem preferência para determinadas espécies ou variedades de plantas em detrimento de outras.

Rotineiramente, os agricultores tomam decisões sobre o manejo, baseados, primeiramente, no que for mais eficiente para garantir o sustento da família. Num cenário de oportunidades de comer- 
cialização, são consideradas as questões de mercado e, por isso, também fatores como o crescimento mais rápido de determinadas espécies e variedades para atender a esse mesmo mercado, o que pode levar podendo levar as preferências alimentares das famílias agricultoras a um segundo plano de prioridade (já que essa preferência pode não ser a mesma do que é exigido pelo mercado). Esse conjunto de fatores formam um cenário propício para que haja redução da diversidade de plantas alimentícias a serem manejadas, pois, ainda que os agricultores conheçam determinadas plantas, o uso é reduzido pela ausência do cultivo ou extração com propensão de crescente redução para as próximas gerações de agricultores.

Além disso, à medida que as práticas agrícolas e extrativistas dessas comunidades locais permitem a continuidade de processos ecológicos importantes para o meio e, ao mesmo tempo, protegem traços socioculturais igualmente importantes, os impedimentos as essas práticas revelam contradições que apontam para o comprometimento da continuidade do uso de uma diversidade de espécies.

Frente ao avanço do desmatamento na região de Ubatuba, é possível que se não existissem as leis de proteção ambiental pertinentes às UCs, a paisagem local seria muito diferente de como se apresenta na atualidade. No entanto, ao tornar ilegítimo o direito ao território e uso dos recursos por parte dos agricultores locais, criam-se outros obstáculos para a conservação da sociobiodiversidade.

A saída encontrada para esse impasse está na criação e/ou reconhecimento de práticas de manejo sustentável, como, por exemplo, as roças tradicionais com uso das técnicas de coivara-cultivo-pousio e do manejo comunitário de espécies ameaçadas de extinção e de importância cultural para as comunidades, como a juçara (Euterpe edulis Mart.). A análise de tais mecanismos e avaliação da sua capacidade conservacionista, bem como a elaboração de estratégias de conservação, deve ser um exercício a ser realizado com a participação das comunidades que devem estar envolvidas e atuando na construção das decisões tomadas (Diegues, 2000; Ansell \& Gash, 2008; Reed, 2008). Para Hanazaki (2003), a conservação in situ de recursos genéticos de plantas, feita de forma dinâmica sem interromper a interação ser humano e planta, somente é possível se houver parceria entre as populações locais que manejam esses recursos.

Apenas no Plano de Manejo do PESM, finalizado em 2008, vê-se que houve um amadurecimento nesse sentido. Após embates que envolveram discussões, conflitos e confrontos por parte das comunidades locais junto ao Estado, foi possível a participação destas na elaboração do Plano de Manejo e no Plano de Uso Tradicional, este último concluído em 2005, (São Paulo, 2008) que regulamenta o uso da ZHCan.

Um outro ponto importante a se considerar são as gerações subsequentes de agricultores. Do grupo de entrevistados, apenas 4 são jovens com idade entre 28-36 anos. Isso leva à preocupação quanto à continuidade do conhecimento nos núcleos familiares, visto que a transmissão dos conhecimentos relativos à vida em comunidades (assim como dos valores, linguagens e visão de mundo) dá-se, em maior parte, a partir da oralidade e da prática diária. O mesmo tipo de comprometimento em transmitir conhecimento foi percebido pelo relato de trabalhos de muitos autores (Mendonça \& Menezes, 2003; Sáez et al., 2003; Costa-Neto et al., 2002). Amorozo (2000) aponta que nos cultivos de mandioca feitos por agricultores tradicionais do estado do Mato 
Grosso houve redução do número de variedades nas roças com influência direta de fatores como a redução do número de jovens agricultores e objetivos ligados à produção de mercado.

Entre os agricultores com idade acima de 40 anos, espécies de plantas com diversos usos são corriqueiramente trocadas e doadas. No caso das alimentícias, estas são poupadas durante as roçadas, capinas e derrubadas. Dessa forma, os caiçaras têm seus bancos de germoplasma nas suas áreas e nas áreas dos vizinhos com material sendo constantemente reproduzido e utilizado, estando disponível para o doador em caso de perda. Segundo Clement et al. (2000), esse tipo de estratégia de conservação on farm, é assegurado desde que haja uso: enquanto houver interesse dos agricultores, haverá conservação desse material.

Os agricultores frequentemente manterão suas variedades consigo mesmo tendo à disposição variedades modernas (proveniente de melhoramento vegetal). Isto ocorre devido a fatores ligados ao conhecimento que esses agricultores possuem acerca de características ecológicas, sociais e econômicas de seus ambientes (Alavarez et al., 2005; Bellon et al., 2015; Coomes et al., 2015; Narloch et al., 2017), tais como: épocas de cultivo e colheita; a cooperação entre agricultores com as trocas de espécies e de trabalho; a descoberta de novos usos para partes das plantas (como ocorreu com a juçara); entre outros.

No caso da juçara (incluída na lista de espécies ameaçadas de extinção com grande importância ecológica), por exemplo, a descoberta do processamento do fruto para produção de uma bebida similar ao famoso açaí amazônico, em vez da derrubada da planta para extração do palmito, trouxe um novo campo de trabalho para os agricultores, baseado no manejo florestal comunitário (IPEMA, 2019).
Essa iniciativa de diversificação de uso possibilitou a geração de renda pela comercialização no mercado local e consumo na merenda escolar de escolas municipais de Ubatuba (IPEMA, 2019), o incentivo à manutenção das plantas existentes e cultivo de novas plantas de juçara. Nesse caso, houve uma inversão da lógica mercadológica. Partiu do manejo comunitário, de uma espécie com valor cultural e ecológico, à abertura de uma nova frente de mercado. Os agricultores incutiram uma preferência para o mercado baseado nas necessidades e preferências, primeiramente, dos agricultores. Não foi o mercado que impôs aos agricultores qual espécie deveria ser cultivada caso eles quisessem obter renda pela comercialização.

Tais mecanismos implicam na manutenção de variedades que correriam o risco de desaparecer se não fossem continuamente cultivadas, o que reforça a ideia de que esses fatores podem auxiliar na elaboração de estratégias que fomentem a conservação in situ de plantas alimentícias para serem considerados em planos de gestão, seja por meio dos Planos de Manejo, Políticas e Programas públicos ou de qualquer outro instrumento utilizado com o objetivo de alcançar ou promover a conservação da sociobiodiversidade.

\section{Considerações finais}

Os agricultores põem em uso uma diversidade de espécies com técnicas locais particulares (relativas à comunidade), manejando intensamente essas espécies e espaços. A combinação desses fatores mostrou que a diversidade de espécies nas áreas dos agricultores caiçaras é alta, estando muito próximas às das áreas que foram abandonadas e estavam em estágio avançado de recuperação. 
Os agricultores caiçaras mostraram grande similaridade entre si, tanto na forma de manejar suas áreas quanto nos processos que envolvem a conservação das plantas alimentícias. Ainda que o cultivo de variedades (e até de espécies) de plantas esteja sendo fortemente influenciado pelas preferências dos consumidores de Ubatuba, existem os hábitos alimentares e a herança cultural como fatores importantes para a seleção das plantas que permanecem sendo cultivadas ou extraídas da mata - fatores apontados aqui como uma forma de "controle" do agroecossistema. Dessa forma, é relevante que esses fatores possam ser investigados em pesquisas futuras aprofundadas especificamente nesses pontos.

Além disso, o tipo de modificação e forma de recuperação que a paisagem vem sofrendo desde a implantação das unidades de conservação apontam para a importância da ação conjunta entre as leis ambientais e as práticas tradicionais da população local. Tais fatores reiteram a afirmação que muitos trabalhos científicos da área vêm atribuindo a essas populações: a de que todo e qualquer plano de manejo, assim como políticas públicas e leis relacionadas, tenham a participação efetiva das populações locais. Dessa forma, consideramos que a ampla discussão sobre as decisões que influenciam na conservação da sociobiodiversidade precisam dar espaço ativo para os atores que já desenvolvem o manejo comunitário sustentável.

\section{Referências}

Albuquerque, U. P. de; Lucena, R. F. P. de (Org). Métodos e técnicas na pesquisa etnobotânica. Recife: Livro Rápido/ NUPEEA, 2004.
Allegretti, M. A construção social de políticas públicas. Chico Mendes e o movimento dos seringueiros. Desenvolvimento e Meio Ambiente, 18, 39-59, 2008.

Altieri, M. A. Linking ecologists and traditional farmers in the search for sustainable agriculture. Frontiers in Ecology and the Environment, 2, 35-42, 2004.

Altieri, M.; Toledo, M. The agroecological revolution in Latin America: rescuing nature, ensuring food sovereignty and empowering peasants. The Journal of Peasant Studies, 38(3), 587-612, 2011.

Almeida, S. S.; Amaral, D. D.; Silva, A. S. L. Estrutura e fitossociologia de florestas de várzea no estuário amazônico. ECOLAB. CD ROOM, 2002.

Alavarez, N.; Garine, E; Khasah, C. et al. Farmers' practices, metapopulation dynamics, and conservation of agricultural biodiversity on-farm: a case study of sorghum among the Duupa in sub-sahelian Cameroon. Biological Conservation, 121, 533-543, 2005.

Amaral, C. N. do; Neto, G. G. Os quintais como espaços de conservação e cultivo de alimentos: um estudo na cidade de Rosário Oeste (Mato Grosso, Brasil). Boletim Museu Paranaenese Emílio Goeldi. Ciências Humanas, 3(3), 2008.

Amorozo, M. C. M. Management and conservation of Manihot esculenta Crantz germoplasm by tradicional farmers into Santo Antonio do Leverger Mato Grosso State, Brazil, Etnoecológica, 4(6), 69-83, 2000.

Anaya, F. C.; Espirito-Santo, M. M. Protected areas and territorial exclusion of traditional communities: analyzing the social impacts of environmental compensation strategies in Brazil. Ecology and Society, 21, 1. ed, 2018.

Ansell, C.; Gash, A. Collaborative Governance in Theory and Practice. Journal of Public Administration Research and Theory, 18, 4. ed., 543-571, 2008

Balmford, A.; Bennun, L.; ten Brinc, B. et al. The convention on biological diversity's 2010 target. Science, 307(5707), 212-213, 2005.

Bellon, M. R.; Gotor, E.; Caracciolo, F. Conserving landraces and improving livelihoods: how to assess the success of on-farm conservation projects? International Journal of Agricultural Sustainability, 13(2),167-182, 2015. 
Bernard, H. R. Research Methods in Cultural Anthropology. Altamira Press, USA, $4^{\mathrm{a}}$ ed., 2006.

Bernholt, H.; Kehlenbeck, K.; Gebauer, J.; Buerkert, A. Plant species richness and diversity in urban and peri-urban gardens of Niamey, Niger. Agroforest System, 77(159), 2009.

Berkes, F.; Colding, J.; Folke, C. Navigating Social-Ecological Systems: Building Resilience for Complexity and Change. Cambridge University Press, USA, 2003.

Beveridge, M. C. M.; Thilsted, S. H.; Phillips, M. G. Meeting the food and nutrition needs of the poor: the role of fish and the opportunities and challenges emerging from the rise of aquaculture, Journal of Fish Biology, 83, 10671084, 2013.

Bisol, C. A. Estratégias de pesquisa em contextos de diversidade cultural: entrevistas de listagem livre, entrevistas com informantes-chave e grupos focais. Estudos de Psicologia, 29(1), 719-726, 2012.

Brasil. ICMBio- Instituto Chico Mendes de Conservação da Biodiversidade, 2014. Disponível em: $<$ http://www.icmbio. gov.br/parnaserradabocaina/extras/62-plano-de-manejo-e-monitorias.html>. Acesso em jun. 2014.

Brasil. IPEA. Instituto de Pesquisa Econômica Aplicada. Ministério da Economia, 2019. Disponível em: < http:// www.ipeadata.gov.br/Default.aspx>. Acesso em: out. 2019.

Brussaard, L.; Caron, P.; Campbell, B. et al. Reconciling biodiversity conservation and food security: scientific challenges for a new agriculture. Current Opinion in Environmental Sustainability, 2, 34-42, 2010.

Buschbacher, R. A Teoria da Resiliência e os Sistemas Socioecológicos: como se preparar para um futuro imprevisível? Boletim Regional, Urbano e Ambiental, 9, 2014.

Butchart, S. H. M.; Walpole, M.; Collen, B. et al. Global Biodiversity: Indicators of Recent Declines. Science, 328(5982), 1164-1168, 2010.

Campos, M. C. R., Tamashiro, J. Y., Assis, M. A.; Joly, C. A. Florística e fitossociologia do componente arbóreo da transição Floresta Ombrófila Densa das Terras Baixas - Floresta Ombrófila Densa Submontana do Núcleo Picinguaba/ PESM, Ubatuba, sudeste do Brasil. Biota Neotropica,
11(2), 2011.

Carvalho, A. V. Memórias ambientais e Rodovia Rio-Santos: patrimônio e fontes orais no litoral Norte de São Paulo, 2014. Biblioteca Virtual FAPESP. Disponível em:<http:// www.bv.fapesp.br/pt/auxilios/35265/memorias-ambientais-e-rodovia-rio-santos-patrimonio-e-fontes-orais-no-litoral-norte-de-sao-paulo/>. Acesso em: jun. 2014.

Carvalho, F. A.; Nascimento, T. M.; Braga, J. M. A. Estrutura e composição florística do estrato arbóreo de um remanescente de Mata Atlântica Submontana no município de Rio Bonito, RJ, Brasil (Mata Rio Vermelho), Revista Árvore, 31(4), 717-730, 2007.

Casas, A.; Caballero, J.; Mapes, C.; Zárate, S. Manejo de La vegetación, domesticación de plantas y origen de la agricultura en Mesoamérica. Boletín Sociedad Botanica do Mexico, 61, 31-47, 1997.

Casas, A.; Otero-Arnaiz, A.; Pérez-Negrón, E.; Valiente-Banuet, A. In situ Management and Domestication of Plants in Mesoamerica. Annuals of Botany, 100, 1001-115, 2007

Clement, C. 1492 and the loss of Amazonian crop genetic resources. I. The relation between domestication and human population decline. Economic Botany, 53(2),188-202, 1999.

Clement, C.; Rocha, S. F. R.; Cole, D. M.; Vivan, J. L. Conservação on farm. In: Nass, L. L. (Ed.). Recursos genéticos vegetais. Embrapa Recursos Genéticos e Biotecnologia, Brasília, DF, 2000.

Coomes, O. T.; McGuire, S. J.; Garine, E. et al. Farmer seed networks make a limited contribution to agriculture? Four common misconceptions. Food Policy, 56, 41-50, 2015.

Costa-Neto, E. M.; Dias, C. V.; Melo, M. N. O conhecimento ictiológico tradicional dos pescadores da cidade de Barra, região do médio São Francisco, Estado Barra, região do médio São Francisco, Estado da Bahia. Acta Scientiarum, 24(2), 561-572, 2002.

Dawson, I. K.; Leakey, R.; Clement, C. R. et al. The management of tree genetic resources and the livelihoods of rural communities in the tropics: Non-timber forest products, smallholder agroforestry practices and tree commodity crops. Forest Ecology and Management, 333, 9-21, 2014.

Diegues, A. C. Etnoconservação da Natureza: enfoques 
alternativos. In: Diegues, A. C. (Org.). Etnoconservação: Novos rumos para a proteção da natureza nos trópicos. Editora Hucitec, NUPAUB-USP, 2000.

Evans, L. T. Crop, evolution, adaptation and yield. Cambridge: Cambridge University Press., 1996.

Faith, D. P.; Magallón, S.; Hendry, A.P. et al. Ecosystem Services: an evolutionary perspective on the links between biodiversity and human well-been. Current Opinion on Environmental Sustainability, 2, 66-74, 2010.

Faria, J. C.; Grosjean, P.; Jelihovschi, E. Tinn-R Editor GUI for $R$ Language and Environment, 2014. Disponível em: $<$ http://nbcgib.uesc.br/lec/software/editores/tinn-r/en>. Acesso em: maio 2014.

Farrall, M. H. O Conceito e Resiliência no contexto dos sistemas sócio-ecológicos. Ecologia ,6, 50-62, 2012.

Ferreira, L. C.; Siviero, S. O.; Campos, S. V. et al. Conflitos Sociais em Áreas Protegidas no Brasil: Moradores, Instituições e ONGs no Vale do Ribeira e Litoral Sul, SP. Revista Idéias, 8(2), 115-149, 2001.

Ferreira, M. C.; Jardim, M. A. G. Algumas espécies vegetais usadas pelos moradores da Ilha de Algodoal, Maiandeua, Município de Maracanã, Pará. Boletim Museu Paranaense Emílio Goeldi. Ciências Naturais, 1(2), 45-51, 2005.

Fischer, J.; Hartel, T.; Kuemmerle, T. Conservation policy in traditional farming landscapes, Conservation Letters, 5 , 167-175, 2012.

Foppa, C. C.; Barreto, G. C.; Veras Neto, F. Q.; Medeiros, R. P. A(re)categorização de unidades de conservação e suas implicações aos modos de vida tradicionais. Desenvolvimento e Meio Ambiente, Edição especial: 30 Anos do Legado de Chico Mendes, 48, 343-366, 2018.

Galluzzi, G.; Eyzaguirre, P.; Negri, V. Home gardens: neglected hotspots of agro-biodiversity and cultural diversity. Biodiversity Conservation, 19, 3635-3654, 2010.

Hammer, O.; Harper, D. A. T.; Ryan, P. D. PAST: Paleontological statistics software package for education and data analysis. Palaeontologia Electronica, 4(1), 2001. Disponível em: $<$ http://palaeo-electronica.org/2001>

Hanazaki, N. Comunidades, conservação e manejo: o papel do conhecimento ecológico local. Biotemas, 16(1), 23-47, 2003.

Hanazaki, N.; Castro, F.; Oliveira, V. G.; Peroni, N. Between the sea and the land: the livelihood of estuarine people in southeastern Brazil. Ambiente \& Sociedade, 3, 2007.

IPEMA, Instituto de Permacultura e Ecovilas da Mata Atlântica, 2019. Disponível em: <http://ipemabrasil.org.br/ projetos/>. Acesso em: out. 2019.

Jackson, L. E.; Pulleman, M. M.; Brussaard, L. et al. Social-ecological and regional adaptation of agrobiodiversity management across a global set of research regions. Global Environmental Change, 22(3), 623-639, 2012.

Johns, T.; Powell, B.; Maundu, P.; Eyzaguirre, P.B. Agricultural biodiversity as a link between traditional food systems and contemporary development, social integrity and ecological health. Journal of Science of Food Agriculture, 93, 3433-3442, 2013.

Kinupp, V. F.; Barros, I. B. I. Levantamento de dados e divulgação do potencial das Plantas alimentícias alternativas no Brasil. Horticultura Brasileira, 22(2), 2004.

Lacerda, M. S. Composição florística e estrutura da comunidade arbórea num gradiente altitudinal da Mata Atlântica. Campinas, Tese (Doutorado em Biologia Vegetal)-UNICAMP, 2001.

Little, P. E. Territórios Sociais e Povos Tradicionais no Brasil: Por uma Antropologia da Territorialidade. Série Antropologia, 322, 2002.

Macedo, G. S. S. R.; Ming, L. C. Espécies alimentícias manejadas por caiçaras do Sertão do Ubatumirim (São Paulo), Sudeste do Brasil. Bioikos, 30(1), 1-17, 2016.

Mendonca Filho, R. F. W; Menezes, F. S. Estudo da utilização de plantas medicinais pela população da Ilha Grande - RJ. Revista Brasileira de Farmacognosia, 13(1), 55-58, 2003.

Morais, F. F., Morais, R. F.; da Silva, C. J. Conhecimento ecológico tradicional sobre plantas cultivadas pelos pescadores da comunidade Estirão Comprido, Pantanal Matogrossense, Brasil. Boletim Museu Pararanense Emílio Goeldi, Ciências Humanas, 4(2), 277-294, 2009. 
Moreno-Calles, A. I.; Casas, A.; Rivero-Romero, A. D. et al. Ethnoagroforestry: integration of biocultural diversity for food sovereignty in Mexico. Journal of Ethnobiology and Ethnomedicine, 12(54), 2016.

Myers, N.; Mittermeier, R. S.; Fonseca, G. A. B.; Kent, J. Biodiversity hotspot for conservation priorities. Nature, 403, 2000.

Narloch, U.; Drucker, A. G.; Pascual, U. What role for cooperation in conservation tenders? Paying farmer groups in the High Andes. Land Use Policy, 63, 659-671, 2017.

Nenadic, O., Greenacre, M. Correspondence Analysis in R, with two and three dimensional graphics: The capackage. Journal of Statistical Software, 20(3), 1-13, 2007.

Ng'endo, N.; Keding, G. B.; Bhagwat, S.; Kehlenbeck, K. Variability of On-Farm Food Plant Diversity and Its Contribution to Food Security: A Case Study of Smallholder Farming Households in Western Kenya. Agroecology and Sustainable Food Systems, 39, 1071-1103, 2015.

Ostergard, H.; Finckh, M. R.; Fontaine, L. et al. Time for a shift in crop production: embracing complexity through diversity at all levels. Journal of the Science of Food Agriculture, 89, 1439-1445, 2009.

Peroni, N. Ecologia e Genética da mandioca na agricultura itinerante do Litoral Sul Paulista: uma análise espacial e temporal. Campinas, Tese (Doutorado em Biologia Vegetal)- UNICAMP, 2004.

Peroni, N.; Hanazaki, N. Current and lost diversity of cultivated varieties, especially cassava, under swidden cultivation systems in the Brazilian Atlantic Forest. Agriculture, Ecosystems and Environment, 92(2-3), 171-183, 2002.

Peroni, N.; Martins, P.S. Influência da dinâmica itinerante na geração da diversidade de etnovariedades cultivadas vegetativamente. Interciência, 25(1), 22-29, 2000.

Pessoa, M. F.; Guerra, A. M. N. M.; Maracajá, P. B.; Lira, J. F. B.; Filho, E. T. D. Estudo da cobertura vegetal em ambientes da caatinga com diferentes formas de manejo no Assentamento Moacir Lucena, Aponi-RN. Revista Caatinga, 21(3), 40-48, 2008.

Phillips, O.; Gentry, A. H. The Useful Plants of Tambopata, Peru: I. Statistical Hypotheses Tests with a New Quantitative
Technique. Economic Botany, 47(1), 15- 32, 1993.

Pilla, M. A. C.; Amorozo, M. C. M. O conhecimento sobre os recursos vegetais alimentares em bairros rurais no Vale do Paraíba, SP, Brasil. Acta Botanica Brasilica, 23(4), 1190-1201, 2009.

R Core Team R: A language and environment for statistical computing. R Foundation for Statistical Computing, Vienna, Austria, 2014. URL Disponível em: http://www.R-project. org/. Acesso em: maio 2014.

Ratnadass, A.; Fernandes, P.; Avelino, J.; Habib, R. Plant species diversity for sustainable management of crop pests and diseases in agroecosystems: a review. Agronomy Sustainable Development, 32, 273-303, 2012.

Raymond, C. M.; Bryan, B. A.; MacDonald, D. H. et al. Mapping community values for natural capital and ecosystem services. Ecological Economics, 68, 1301-1315, 2009.

Reed, J.; Van Vianen, J.; Deakin, E. et al. Integrated landscape approaches to managing social and environmental issues in the tropics: learning from the past to guide the future. Global Change Biology, 22, 2540-2554, 2016.

Reed, M. S. Stakeholder participation for environmental management: A literature review. Biological Conservation, 141(10), 2417-2431, 2008.

Ruiz-Pérez, M; Belcher, B.; Achdiawan, R. et al. Markets Drive the Specialization Strategies of Forest Peoples, Ecology and Society, 9(2), 2004.

Sáez, O. C.; Navieira, M. C.; Gil, L. P. O Saber é Estranho e Amargo: Sociologia e mitologia do conhecimento entre os Yaminawa. Campos, 4, 9-28, 2003.

Sampaio, M. F. A; Kepple, A.; Segal-Correa, A. M. et al. Segurança Alimentar: experiência de grupos focais com populações rurais do Estado de São Paulo, Segurança Alimentar e Nutricional, 13(1), 64-77, 2006.

Sanchez, M.; Pedroni, F.; Leitão-Filho, H. F.; Cesar, O. Composição florística de um trecho de floresta ripária na Mata Atlântica em Picinguaba, Ubatuba, SP. Revista Brasileira de Botânica, 22(1), 1999.

São Paulo (Estado). Instituto Florestal do Estado de São Paulo (IF). Plano de Manejo do Parque Estadual da Serra 
do Mar. Secretaria do Estado do Meio Ambiente (SEMA). São Paulo, 2008. Disponível em: < http://www.iflorestal. sp.gov.br/Plano_de_manejo/PE_SERRA_MAR/Plano_de Manejo_Pe_Serra_do_Mar.pdf $>$. Acesso em: ago. 2012.

São Paulo (Estado). Fundação SEADE, IMP-Informações dos Municipios Paulistas, 2019. Disponível em: < http:// www.imp.seade.gov.br/frontend/\#/>. Acesso em: out. 2019.

Santos, G. C.; Jardim, M. A. G. Florística e estrutura do estrato arbóreo de uma floresta de várzea no município de Santa Bárbara do Pará, Estado do Pará, Brasil. Acta Amazonica, 36(4), 437- 446, 2006.

Saxena, A. K.; Fuentes, X. C.; Herbas, R. G.; Humphries, D. L. Indigenous Food Systems and Climate Change: Impacts of Climatic Shifts on the Production and Processing of Native and Traditional Crops in the Bolivian Andes. Frontiers in Public Health, 4, 2016.

Schroth, G.; Mota, M. S. S. Technical and Institutional Innovation in Agroforestry for Protected Areas Management in the Brazilian Amazon: Opportunities and Limitations. Environmental Management, 52, 427-440, 2013.

Silva, A. F. Composição florística e estrutura de um trecho de Mata Atlântica de encosta no município de Ubatuba, São Paulo. Viçosa, Dissertação (Mestrado em Ecologia)UFV, 1980.

Silva, D. S. Uso dos Recursos Naturais em Unidades de Conservação de Proteção Integral: O caso do sertão do Ubatumirim, Núcleo Picinguaba do Parque Estadual da Serra do Mar. Presidente Prudente, Monografia (Bacharelado em Geografia)-UNESP, 2010.
Silva, S. R. Populações tradicionais camponesas, um estudo de território, identidade, problemas ambientais e fundiários. $\mathrm{O}$ caso de Camburi-Ubatuba-SP. In: Anais do X Encontro de Geógrafos da América Latina. Universidade de São Paulo, 2005. Disponível em: http: $</ /$ observatoriogeograficoamericalatina.org.mx/egal10/Geografiasocioeconomica/ Geografiacultural/50.pdf > . Acesso em: jan. 2019.

Simões, E.; Ferreira, L. C.; Joly, C. A. O Dilema de Populações Humanas em Parques: Gestão Integrada entre Técnicos e Residentes no Núcleo Picinguaba. Sustentabilidade em Debate, 2(1), 17-32, 2011.

Siqueira, P. Genocídio dos Caiçaras. São Paulo: Massao Ohno e Ismael Guarnelli Editores, 1. ed., 1984.

Shen, S.; Xu, G.; Li, D. et al. Agrobiodiversity and in situ conservation in ethnic minority communities of Xishuangbanna in Yunnan Province, Southwest China. Journal of Ethnobiology and Ethnomedicine,13(28), 2017.

Suzuki, J. C.; Freitas, M. V. G.; Souza, D. M. Memória da Roça Caiçara e modo de vida das comunidades de Pedrinhas (Ilha Comprida) e São Paulo Bagre (Cananéia). Revista Faz Ciência, 12(15), 33-54. 2010.

Taylor, J. P.; Evers, S.; McKenna, M. Determinants of healthy eating in children and youth. Canadian Journal of Public Health-Revenue Canadienne de Sante Publique, 96, S20-S26, 2005.

Thrupp, L. A. Linking Agricultural Biodiversity and Food Security: The Valuable Role of Agrobiodiversity for Sustainable Agriculture. International Affairs, 76, 283-297, 2000. 